\title{
Characterization of an OmpA-like outer membrane protein of the acidophilic iron-oxidizing bacterium, Acidithiobacillus ferrooxidans
}

\author{
Mohammed Abul Manchur • Mei Kikumoto • \\ Tadayoshi Kanao · Jun Takada $\cdot$ Kazuo Kamimura
}

Received: 17 January 2011/ Accepted: 23 March 2011/Published online: 7 April 2011

(C) The Author(s) 2011. This article is published with open access at Springerlink.com

\begin{abstract}
An OmpA family protein (FopA) previously reported as one of the major outer membrane proteins of an acidophilic iron-oxidizing bacterium Acidithiobacillus ferrooxidans was characterized with emphasis on the modification by heat and the interaction with peptidoglycan. A $30-\mathrm{kDa}$ band corresponding to the FopA protein was detected in outer membrane proteins extracted at $75^{\circ} \mathrm{C}$ or heated to $100^{\circ} \mathrm{C}$ for $10 \mathrm{~min}$ prior to sodium dodecyl sulfate-polyacrylamide gel electrophoresis (SDS-PAGE). However, the band was not detected in outer membrane proteins extracted at $\leq 40^{\circ} \mathrm{C}$ and without boiling prior to electrophoresis. By Western blot analysis using the polyclonal antibody against the recombinant FopA, FopA was detected as bands with apparent molecular masses of 30 and $90 \mathrm{kDa}$, suggesting that FopA existed as an oligomeric form in the outer membrane of A. ferrooxidans. Although
\end{abstract}

Communicated by A. Driessen.

Electronic supplementary material The online version of this article (doi:10.1007/s00792-011-0371-6) contains supplementary material, which is available to authorized users.

M. A. Manchur · M. Kikumoto · T. Kanao - K. Kamimura ( $\square)$ Division of Bioscience, Graduate School of Natural Science and Technology, Okayama University, 3-1-1 Tsushima-Naka, Okayama 700-8530, Japan

e-mail: kamimura@cc.okayama-u.ac.jp

J. Takada

Division of Chemical and Biological Technology, Graduate School of Natural Science and Technology, Okayama University, 3-1-1 Tsushima-Naka,

Okayama 700-8530, Japan

Present Address:

M. A. Manchur

Department of Microbiology, Faculty of Biological Science,

Chittagong University, Chittagong 4331, Bangladesh the fopA gene with a sequence encoding the signal peptide was successfully expressed in the outer membrane of Escherichia coli, the recombinant FopA existed as a monomer in the outer membrane of E. coli. FopA was detected in peptidoglycan-associated proteins from A. ferrooxidans. The recombinant FopA also showed the peptidoglycan-binding activity.

Keywords Acidithiobacillus ferrooxidans . Iron-oxidizing bacterium - Acidophile .

Outer membrane protein $\cdot$ OmpA

\section{Introduction}

The outer membrane of Gram-negative bacterium acts as a molecular sieve that allows the passage of ions and small hydrophilic organic molecules. This property is due to the presence of a major group of proteins, porins, which form diffusion pores (Jap and Walian 1996; Koebnik et al. 2000; Achouak et al. 2001; Schulz 2002; Nikaido 2003). The first identified porins were OmpC and OmpF of the Gramnegative bacterium Escherichia coli, but at present specific and non-specific pore-forming proteins have been found throughout prokaryotes. The OmpA protein is also one of the major proteins in the outer membrane of $E$. coli (Smith et al. 2007). Either a closely related homolog of this protein or a more distantly related relative has now been identified as a major protein in the outer membrane of a wide range of Gram-negative bacteria. Although some porins, such as OmpC and OmpF from E. coli, exist as oligomers, OmpA is referred to as "monomeric or slow porins" (Nikaido 2003). The resistance of OmpA to complete denaturation in solution containing SDS is reflected in a characteristic heat-modifiable migration of the protein on SDS-PAGE 
(Heller 1978). The N-terminal region of OmpA from $E$. coli is shown to cross the membrane eight times in antiparallel $\beta$-strands, and forms a small pore. The C-terminal domain is located in the periplasm, and binds to the peptidoglycan. Major physiological functions of the OmpA family proteins include maintenances of the structural integrity and morphology of the cell (Sonntag et al. 1978) and porin activity (Sugawara and Nikaido 1994), as well as a role in bacterial conjugation or phage binding (Morona et al. 1984).

Acidithiobacillus ferrooxidans is a Gram-negative, acidophilic chemolithotrophic bacterium capable of oxidizing ferrous ion and/or reduced inorganic sulfur compounds and is utilized for industrial mining applications (Rawlings 2002; Rohwerder et al. 2003). Because the outer membrane of this bacterium is exposed to strongly acidic environments ( $\mathrm{pH} 2-3$ ), a low $\mathrm{pH}$ can be observed in the periplasmic space (Guiliani and Jerez 2000). Three major outer membrane proteins, having apparent molecular masses of 40,30 , and $20 \mathrm{kDa}$, have been detected in A. ferrooxidans R2 (Rodriguez et al. 1986). The 40- and 20-kDa proteins were suggested to be porins and the $30-\mathrm{kDa}$ protein was thought to be an OmpA family protein. The $40-\mathrm{kDa}$ protein (Omp40) has been characterized in detail (Silva et al. 1992; Guiliani and Jerez 2000). A cytochrome $c$ (Cyc2) has been detected in the outer membrane of iron-grown A. ferrooxidans and was reported to be involved in iron oxidation (Yarzábal et al. 2002, 2004). Tetrathionate hydrolase induced in the outer membrane of tetrathionate-grown A. ferrooxidans has been purified and characterized (Kanao et al. 2007). Thus, the outer membrane of $A$. ferrooxidans is thought not only to act as a molecular sieve, but also to play important roles in the oxidations of ferrous iron and reduced inorganic sulfur compounds. Therefore, studies of the structure and function of the outer membrane proteins and their association with periplasmic and inner membrane proteins may give insights into the clarification of mechanisms involved in ferrous iron and sulfur oxidation, the two fundamental biological reactions important in the bioleaching.

We have preliminarily characterized an OmpA-like protein (designated as FopA) detected in the outer membrane of A. ferrooxidans NASF-1 (Kamimura et al. 2004). Although the N-terminal region of typical OmpA family proteins is shown to cross the membrane eight times in antiparallel $\beta$-strands and to be involved in a pore formation (Smith et al. 2007), an analysis of the amino acid sequence of FopA has revealed that the N-terminal region was shorter than that of typical OmpA family proteins, such as OmpA and OprF from Pseudomonas aeruginosa (Supplementary Fig. 1). Therefore, the porin activity of FopA was not expected. The peptidoglycan-binding domain was conserved in the C-terminal region of FopA.
Since the function of OmpA family proteins in A. ferrooxidans was not characterized in detail, FopA was characterized with emphasis on the modification by heat and the association with peptidoglycan, which are characteristics of OmpA family proteins.

\section{Materials and methods}

Bacterial strain and growth conditions

A. ferrooxidans ATCC 23270 was used in this study and was grown in $9 \mathrm{~K}$ medium supplemented with ferrous sulfate or elemental sulfur as described previously (Wakai et al. 2004). E. coli NovaBlue and BL21(DE3) was grown in Luria-Bertani (LB) medium at $37^{\circ} \mathrm{C}$.

Preparation of detergent-insoluble membrane fraction

Detergent-insoluble membrane fraction (outer membrane fraction) from iron-grown cells was prepared as described previously (Silva et al. 1992) with a slight modification. Cells were harvested by centrifugation, washed three times with $0.1 \mathrm{M} \beta$-alanine- $\mathrm{SO}_{4}{ }^{2-}$ buffer ( $\mathrm{pH} 3.0$ ), twice with $20 \mathrm{mM}$ Tris- $\mathrm{HCl}$ buffer (pH 6.8), suspended in $20 \mathrm{mM}$ Tris- $\mathrm{HCl}$ buffer (pH 6.8) containing phenylmethylsulfonyl fluoride (PMSF; $50 \mu \mathrm{g} / \mathrm{ml}$ ), and then disrupted by sonication. The lysate was centrifuged at $15,000 \times g$ for $10 \mathrm{~min}$ to remove cellular debris. The supernatant was centrifuged at $105,000 \times g$ for $1 \mathrm{~h}$ at $4^{\circ} \mathrm{C}$ to pellet the membrane fraction. The pellet was washed with $20 \mathrm{mM}$ Tris- $\mathrm{HCl}$ buffer $(\mathrm{pH}$ 6.8) containing PMSF, resuspended in $20 \mathrm{mM}$ Tris- $\mathrm{HCl}$ buffer ( $\mathrm{pH}$ 6.8) containing PMSF and $2 \%(\mathrm{w} / \mathrm{v})$ sodium $N$-laurylsarcosine, and incubated for $1 \mathrm{~h}$ at $30^{\circ} \mathrm{C}$. The suspension was centrifuged at $105,000 \times g$ for $1 \mathrm{~h}$ at $4^{\circ} \mathrm{C}$ to pellet the detergent-insoluble membrane fraction. The pellet was washed two times with $20 \mathrm{mM}$ Tris- $\mathrm{HCl}$ buffer ( $\mathrm{pH}$ 6.8) containing PMSF and suspended in the same buffer. The sample was used as the outer membrane fraction. The outer membrane fraction from E. coli was prepared following essentially the same procedure, except that cells were washed in $20 \mathrm{mM}$ Tris- $\mathrm{HCl}$ buffer ( $\mathrm{pH} 7.8$ ).

Amplification and cloning of the fopA gene

The gene encoding FopA protein with or without a signal peptide was amplified by PCR using two primer pairs and genomic DNA of A. ferrooxidans ATCC 23270 as a template. A forward primer (FopAFNdeI; 5'-AGC CCA TATG GAC GGT GGC TAT GTG-3') and a reverse primer (FopARXhoI; 5'-TAT TTG GCT CGA GAT TAC TGA ACG GTC TT- $3^{\prime}$ ) designed on the basis of the genome sequence data of A. ferrooxidans ATCC 23270 were used 
to amplify fopA without the coding sequence for the signal peptide. LA Taq DNA polymerase (Takara Biotechnol., Shiga, Japan) was used to amplify the DNA fragment. The PCR reaction was as follows: 2 min at $95^{\circ} \mathrm{C}$, followed by 30 cycles at $95^{\circ} \mathrm{C}$ for $30 \mathrm{~s}, 56^{\circ} \mathrm{C}$ for $30 \mathrm{~s}$, and $72^{\circ} \mathrm{C}$ for $90 \mathrm{~s}$, and then $6 \mathrm{~min}$ at $72^{\circ} \mathrm{C}$. The PCR-amplified DNA fragments purified from agarose gel using a GENECLEAN Kit (Funakoshi Co. Ltd., Tokyo, Japan) were cloned into pCR2.1-TOPO vector using a TA cloning kit (Invitrogen Corp., Carlsbad, CA, USA). The nucleotide sequence of the inserted fopA was determined as described previously (Wakai et al. 2004). After digesting the plasmid with NdeI and XhoI, the fopA fragment was ligated into pET28a vector (Merck \& Co., Inc., Whitehouse Station, NJ, USA). The ligation product (pET-fopA) was used to transform E. coli NovaBlue and then E. coli BL21(DE3) competent cells. The recombinant clones were selected on LB medium supplemented with kanamycin $(30 \mu \mathrm{g} / \mathrm{ml})$.

A primer pair, FopAFNcoI (5'-TGA CCA TGG AAC ATA TTA AAG GCA TCA AAG-3') and FopARXhoI, was used to amplify fopA with the coding sequence for the signal peptide. The gene was cloned following the same procedure used to clone fopA without the coding sequence of the signal peptide, except that the PCR reaction was as follows: $2 \mathrm{~min}$ at $95^{\circ} \mathrm{C}$, followed by 30 cycles at $95^{\circ} \mathrm{C}$ for $30 \mathrm{~s}, 54^{\circ} \mathrm{C}$ for $30 \mathrm{~s}$, and $72^{\circ} \mathrm{C}$ for $90 \mathrm{~s}$, and then $6 \mathrm{~min}$ at $72^{\circ} \mathrm{C}$ and that $\mathrm{NcoI}$ and $\mathrm{XhoI}$ were used. The plasmid used to transform E. coli NovaBlue and then E. coli BL21(DE3) competent cells was designated pET-sfopA.

Synthesis and purification of recombinant FopA

Cells transformed with pET-fopA plasmid were grown at $25^{\circ} \mathrm{C}$ on LB medium until the culture reached an optical density at $600 \mathrm{~nm}$ of 0.6 , and the synthesis of His-tagged FopA was induced by adding $0.1 \mathrm{mM}$ isopropyl- $\beta$-Dthiogalactopyranoside (IPTG). Cells were further incubated for $5 \mathrm{~h}$ and harvested by centrifugation $(15,000 \times g$, $10 \mathrm{~min})$. The recombinant FopA was purified using a Ni-charged Chelating Sepharose Fast Flow resin (Amersham Biosciences, Bucks, UK) according to the manufacturer's recommendations. After washing the resin with phosphate/ $\mathrm{NaCl}(\mathrm{PN})$ buffer $(20 \mathrm{mM}$ phosphate, $0.5 \mathrm{M}$ $\mathrm{NaCl}$, pH 7.4) containing $100 \mathrm{mM}$ imidazole, the bound protein (His-tagged FopA) was eluted with PN buffer containing $400 \mathrm{mM}$ imidazole. The solution was dialyzed in $10 \mathrm{mM} \beta$-alanine- $\mathrm{SO}_{4}{ }^{2-}$ buffer ( $\mathrm{pH} 3.0$ ) containing $200 \mathrm{mM}\left(\mathrm{NH}_{4}\right)_{2} \mathrm{SO}_{4}$, centrifuged at $105,000 \times g$ for $2 \mathrm{~h}$, and used for a preparation of the antibody and for in vitro assay for FopA-peptidoglycan binding. The synthesis of FopA protein in cells transformed with the pET-sfopA plasmid was induced following the same procedure as described above.
Preparation of peptidoglycan-protein complex

Crude peptidoglycan with associated proteins (peptidoglycan-protein complex) from iron-grown cells was prepared as described previously (Fjellbirkeland et al. 1997), except that $10 \mathrm{mM}$ Tris-HCl buffer ( $\mathrm{pH}$ 6.8) was used. Total membrane was suspended in $10 \mathrm{mM}$ Tris- $\mathrm{HCl}$ buffer ( $\mathrm{pH} 6.8$ ) containing 2\% (w/v) SDS and then was incubated at $40^{\circ} \mathrm{C}$ for $15 \mathrm{~min}$. Crude peptidoglycan with associated proteins was pelleted by centrifugation at $105,000 \times g$ for $60 \mathrm{~min}$. The pellet was resuspended in $10 \mathrm{mM}$ Tris- $\mathrm{HCl}$ buffer ( $\mathrm{pH}$ 6.8), and used as a peptidoglycan-protein complex.

\section{Preparation of peptidoglycan}

Peptidoglycan from iron-grown cells was prepared as described previously (Bouveret et al. 1999). Cells (0.5 g in wet weight) were suspended in $10 \mathrm{ml}$ of $9 \%(\mathrm{w} / \mathrm{v}) \mathrm{NaCl}$, mixed with $10 \mathrm{ml}$ of $8 \%(\mathrm{w} / \mathrm{v}) \mathrm{SDS}$, and incubated for $30 \mathrm{~min}$ at $100^{\circ} \mathrm{C}$. After standing at room temperature overnight, the sample was centrifuged at $105,000 \times g$ for $2 \mathrm{~h}$. The pellet was suspended in $3 \mathrm{ml}$ of water, then washed by four cycles of resuspension and recentrifugation in water, and finally resuspended in $0.5 \mathrm{ml}$ of $10 \mathrm{mM}$ $\beta$-alanine- $\mathrm{SO}_{4}{ }^{2-}$ buffer ( $\mathrm{pH} 3.0$ ).

In vitro assay for FopA-peptidoglycan binding

The assay for lipoprotein-peptidoglycan interaction (Bouveret et al. 1999) was slightly modified and used to examine a binding ability of FopA to peptidoglycan. The recombinant FopA in $10 \mathrm{mM} \beta$-alanine- $\mathrm{SO}_{4}$ buffer $(\mathrm{pH}$ 3.0) containing $200 \mathrm{mM}\left(\mathrm{NH}_{4}\right)_{2} \mathrm{SO}_{4}$ was initially centrifuged at $105,000 \times g$ for $2 \mathrm{~h}$ to pellet insoluble recombinant FopA. The resulting soluble recombinant FopA was used for the binding assay. The recombinant FopA $(10 \mu \mathrm{g} / 20 \mu \mathrm{l})$ and $20 \mu \mathrm{l}$ of purified peptidoglycan preparation were mixed and incubated in $10 \mathrm{mM} \beta$-alanine- $\mathrm{SO}_{4}$ buffer $(\mathrm{pH}$ 3.0) containing $200 \mathrm{mM}\left(\mathrm{NH}_{4}\right)_{2} \mathrm{SO}_{4}$ at room temperature for $1 \mathrm{~h}$ (final volume, $100 \mu \mathrm{l}$ ). The mixture was centrifuged at $105,000 \times g$ for $2 \mathrm{~h}$ to pellet peptidoglycan. The pellet was washed in $500 \mu \mathrm{l}$ of $10 \mathrm{mM} \beta$-alanine- $\mathrm{SO}_{4}$ buffer $(\mathrm{pH}$ 3.0) containing $200 \mathrm{mM}\left(\mathrm{NH}_{4}\right)_{2} \mathrm{SO}_{4}$. After identical centrifugation, the pellet was suspended in $10 \mu \mathrm{l}$ of Laemmli buffer for SDS-PAGE and boiled for $10 \mathrm{~min}$ and proteins in the supernatant were precipitated with cold acetone. The precipitate was collected by centrifugation $(15,000 \times g$, $10 \mathrm{~min}$ ), similarly suspended in Laemmli buffer and boiled for $10 \mathrm{~min}$. The samples were analyzed by SDS-PAGE. As a control experiment, an SQR protein, which catalyzes the oxidation of sulfide and the reduction of quinone in the periplasm of $A$. ferrooxidans (Wakai et al. 2007) and does 
not have a peptidoglycan-binding domain, was employed for the binding assay. The recombinant SQR without a thioredoxin was prepared as described previously (Wakai et al. 2007).

Protein analysis

SDS-PAGE, determinations of N-terminal amino acid sequences, a preparation of polyclonal antibody against the recombinant FopA, and Western blot analysis using the antibody were carried out as described previously (Wakai et al. 2007).

\section{Database analysis}

Blast searches were carried out through The Comprehensive Microbial Resource website at http://cmr.jcvi. org/cgi-bin/CMR/GenomePage.cgi?org=gtf. The sequence data were used to search the DNA and protein databases for homologs through the website at the National Center for Biotechnology Information (NCBI; http://www.ncbi.nlm. nih.gov/BLAST/).

\section{Results}

Detection of outer membrane proteins having variable electrophoretic mobility

The mobility of OmpA from E. coli decreases in polyacrylamide gel containing SDS when the protein is heated to $100^{\circ} \mathrm{C}$ prior to electrophoresis. Protein showing such mobility is called as "heat-modifiable protein". To detect outer membrane proteins having variable electrophoretic mobility, a solubilization of proteins from the outer membrane fraction is required prior to SDS-PAGE analysis. Various detergents, such as $1 \%(\mathrm{w} / \mathrm{v}) N$-dodecyl- $\beta$-Dmaltoside, $1 \%(\mathrm{w} / \mathrm{v})$ octyl- $\beta$-D-glucopyranoside, $5 \%(\mathrm{w} / \mathrm{v})$ Tween 20, and 5\% (w/v) Triton X-100, were used to solubilize proteins from the outer membrane fraction of $A$. ferrooxidans. FopA was not solubilized by incubating the membrane fraction with the detergents described above at $25^{\circ} \mathrm{C}$ for $1 \mathrm{~h}$. Although FopA was solubilized by incubating the membrane with $5 \% \mathrm{SDS}$ at $25^{\circ} \mathrm{C}$ for $15 \mathrm{~min}$, a treatment with $2 \% \mathrm{SDS}$ at $25^{\circ} \mathrm{C}$ for 15 min could not solubilize FopA. On the other hand, a treatment with $8 \%$ SDS at $25^{\circ} \mathrm{C}$ for $15 \mathrm{~min}$ dissociated a FopA complex. Therefore, outer membrane proteins of A. ferrooxidans were extracted by incubating the membrane fraction in solution containing 5\% SDS for $15 \mathrm{~min}$ at different temperatures. The 40- and $30-\mathrm{kDa}$ bands were not detected in the extracts prepared at a temperature of $40^{\circ} \mathrm{C}$ or less, when the extracts without heating to $100^{\circ} \mathrm{C}$ for $10 \mathrm{~min}$ were analyzed by SDS-PAGE (Fig. 1, lanes 1 and 3). They were detected in all extracts heated to $100^{\circ} \mathrm{C}$ for $10 \mathrm{~min}$ prior to electrophoresis and in extracts prepared at temperatures of at least $75^{\circ} \mathrm{C}$ (Fig. 1, lanes 2 and 4-8).

The N-terminal amino acid sequences of the 40- and $30-\mathrm{kDa}$ proteins revealed that the proteins were a trimeric porin (Omp40) and an OmpA-like protein (FopA), respectively. The molecular mass estimated from the deduced amino acid sequence of FopA was 20,197 Da, which was about $10 \mathrm{kDa}$ smaller than the apparent molecular mass determined by SDS-PAGE. The electrophoretic mobility of FopA in polyacrylamide gel suggested that it may be a heat-modifiable protein. If FopA was heatmodifiable, a distinct protein band with a molecular mass smaller than $30 \mathrm{kDa}$ should have been detected in the nonheat-treated extract and this band should disappear when the extract was heated to $100^{\circ} \mathrm{C}$ prior to electrophoresis. However, the corresponding band was not clearly detected in the samples prepared at a temperature of $40^{\circ} \mathrm{C}$ or less (Fig. 1, lanes 1-4), indicating that FopA is not a heatmodifiable protein.

Immuno-detection of native FopA in outer membrane

Since a band corresponding to the native form of FopA was not clearly resolved by SDS-PAGE (Fig. 1), Western blot analysis using the antibody against the recombinant FopA was carried out. When the outer membrane fraction was incubated in $5 \% \mathrm{SDS}$ solution at $25^{\circ} \mathrm{C}$ for $15 \mathrm{~min}$ and analyzed by Western blotting, the antibody reacted to a protein with the apparent molecular mass of about $90 \mathrm{kDa}$.

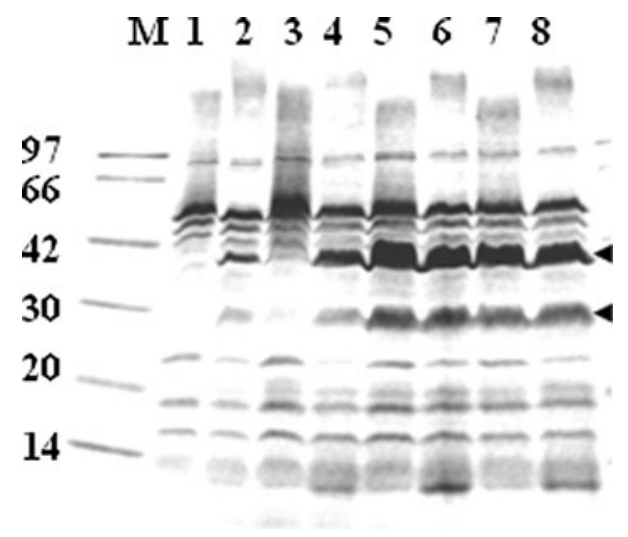

Fig. 1 SDS-PAGE analysis of proteins extracted from detergentinsoluble outer membrane fraction of A. ferrooxidans. Proteins in outer membrane fraction were extracted with 5\% SDS solution at different temperatures. The proteins without boiling prior to electrophoresis (lanes 1, 3, 5, 7) and the boiled proteins (lanes 2, 4, 6, 8) were analyzed by SDS-PAGE and stained with Coomassie Blue. Lanes 1,2 , extracted at $25^{\circ} \mathrm{C}$; lanes 3,4 , extracted at $40^{\circ} \mathrm{C}$; lanes 5,6 , extracted at $75^{\circ} \mathrm{C}$; lanes 7,8 , extracted at $100^{\circ} \mathrm{C}$. Molecular masses in $\mathrm{kDa}$ are indicated on the left. Lane $M$ marker proteins. Arrowheads indicated Omp40 (40 kDa) and FopA (30 kDa) 


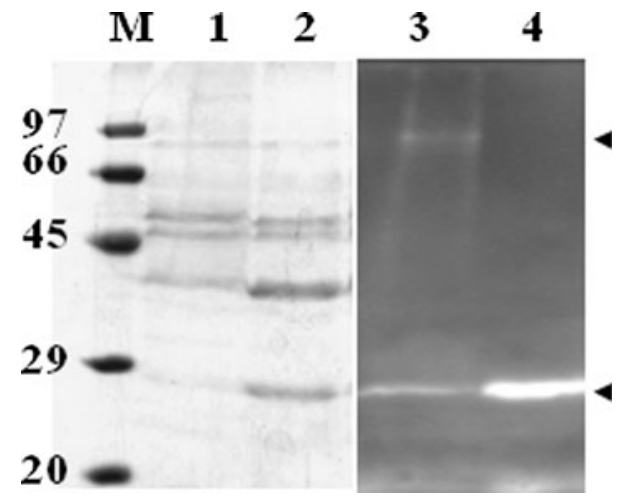

Fig. 2 Western blot analysis of proteins in outer membrane fraction of A. ferrooxidans. Outer membrane proteins were extracted at $25^{\circ} \mathrm{C}$ in the presence of 5\% SDS. The proteins not boiled (lanes 1 and 3) or boiled (lanes 2 and 4 ) prior to electrophoresis were analyzed by SDSPAGE. Proteins were detected by Coomassie Blue staining (lanes 1 and 2) or subjected to Western blot analysis using the polyclonal antibody against the recombinant FopA (lanes 3 and 4). Molecular masses in $\mathrm{kDa}$ are indicated on the left. Lane $M$ marker proteins

A protein with the apparent molecular mass of about $30 \mathrm{kDa}$, corresponding to the molecular mass of the denatured FopA (Fig. 2, lane 3), also weakly reacted to the antibody. The $90-\mathrm{kDa}$ band disappeared and the 30-kDa band with a strong signal appeared in the sample heated to $100^{\circ} \mathrm{C}$ (Fig. 2, lane 4), indicating that FopA formed an oligomeric complex in the outer membrane of A. ferrooxidans.

Since syntheses of Cyc2 and tetrathionate hydrolase have been affected by substrates for growth, the amount of FopA in iron-grown or sulfur-grown cells was examined using Western blot analysis. The significant difference in the amount of FopA between two cells was not observed, indicating that the synthesis of FopA was not affected by the substrates.

\section{Characterization of FopA synthesized in E. coli}

The fopA gene with the coding sequence for the signal peptide was expressed in E. coli [BL21(DE3)]. A larger amount of recombinant FopA was remained in the cytoplasm as inclusion bodies, but a little amount of recombinant FopA was detected in the outer membrane fraction, indicating that the signal peptide was successfully recognized by the $E$. coli signal peptidase. Irrespective of heatdenaturation prior to electrophoresis, a protein with the apparent molecular mass of $30 \mathrm{kDa}$ reacted to the antibody (Fig. 3, lanes 3 and 4). OmpA of E. coli, which was identified based on the $\mathrm{N}$-terminal amino acid sequence, clearly showed a heat-modifiable characteristic (Fig. 3, lanes 1 and 2, indicated by arrows), but the recombinant FopA did not show the characteristic.



Fig. 3 SDS-PAGE and Western blot analyses of recombinant FopA synthesized in the E. coli outer membrane. The outer membrane prepared from $E$. coli with pET-sfopA was analyzed by SDS-PAGE. The samples not boiled (lanes 2 and 4 ) or boiled (lanes 1 and 3) prior to electrophoresis were analyzed. Proteins were stained with Coomassie Blue (lanes 1 and 2) or subjected to Western blot analysis using the polyclonal antibody against the recombinant FopA (lanes 3 and 4). Molecular masses in $\mathrm{kDa}$ are indicated on the left. Lane $M$ marker proteins

\section{Interaction of FopA with peptidoglycan}

Since FopA has a peptidoglycan-binding domain in the C-terminal region, the protein is expected to be recovered in a peptidoglycan-protein complex from A. ferrooxidans. When 5\% SDS was used to prepare the peptidoglycanprotein complex, FopA was solubilized from the outer membrane fraction as shown in Fig. 1. Therefore, the peptidoglycan-protein complex was prepared by incubating the membrane fraction (involving inner and outer membranes) in $2 \%$ SDS solution at $40^{\circ} \mathrm{C}$ for $15 \mathrm{~min}$. Western blot analysis of the sample clearly revealed the involvement of FopA in the complex (Fig. 4, lane 3). Two major proteins with apparent molecular masses of 50 and $40 \mathrm{kDa}$ were also detected in the complex (Fig. 4, lane 2). The N-terminal sequences were determined to be LPSFARQ for $50-\mathrm{kDa}$ protein and ADTSNADT for $40 \mathrm{kDa}$ protein. Blast searches revealed that the $50-\mathrm{kDa}$ protein and the 40-kDa protein were Cyc2 (Yarzábal et al. 2002) and Omp40 (Guiliani and Jerez 2000), respectively.

The recombinant FopA and the peptidoglycan prepared from A. ferrooxidans were used to examine their interaction in vitro. The experiments were carefully carried out under the physiological $\mathrm{pH}$ ( $\mathrm{pH}$ 3.0). When fopA without the coding sequence for the signal peptide was expressed in E. coli [BL21(DE3)], the recombinant protein was synthesized in cytoplasm in a soluble form. When the recombinant FopA was incubated with the peptidoglycan from A. ferrooxidans, the protein was recovered in the 




Fig. 4 Detection of FopA in peptidoglycan-protein complex from A. ferrooxidans. Proteins in the peptidoglycan-protein complex were analyzed by SDS-PAGE (lane 2). A peptidoglycan (lane 1) prepared from A. ferrooxidans ATCC 23270 were also analyzed. Proteins were stained with Coomassie Blue (lanes 1 and 2) or subjected to Western blot analysis using the polyclonal antibody against the recombinant FopA (lane 3). Molecular masses in $\mathrm{kDa}$ are indicated on the left. Lane $M$ marker proteins

pellet after an ultracentrifugation at $105,000 \times g$ for $2 \mathrm{~h}$ (Fig. 5, lane 2). When $10 \mu \mathrm{g}$ of the recombinant FopA was used in the experiment, all the protein interacted with the peptidoglycan in the experimental condition employed. When $30 \mu \mathrm{g}$ of the recombinant FopA was used in the binding experiments, the protein was detected both in the supernatant and in the pellet obtained by the ultracentrifugation at $105,000 \times g$ for $2 \mathrm{~h}$. FopA derived from A. ferrooxidans ATCC 23270 was not detected in the peptidoglycan used in the experiment (Fig. 5, lane 3). The recombinant FopA was not also detected in the pellet resulting from the ultracentrifugation of the recombinant FopA at $105,000 \times g$ for $2 \mathrm{~h}$ (Fig. 5, lane 4). When the recombinant SQR, lacking the peptidoglycan-binding domain, was used to discard a possibility of an unspecific binding of the recombinant FopA to the peptidoglycan, the binding of the SQR to the peptidoglycan was not observed. Therefore, the detection of the FopA protein in the pellet obtained by the ultracentrifugation (Fig. 5, lane 2) indicated a specific binding of the recombinant FopA to the peptidoglycan.

\section{Discussion}

Most of the outer membrane proteins appear to be channelforming proteins, and they are classified as porins and specific channels. Omp40 and FopA were detected as the major membrane proteins in the outer membrane of A. ferrooxidans. Omp40 has been assumed to function as a specific channel, because it is a homolog of classical porins, OmpF and OmpC in E. coli (Guiliani and Jerez 2000).

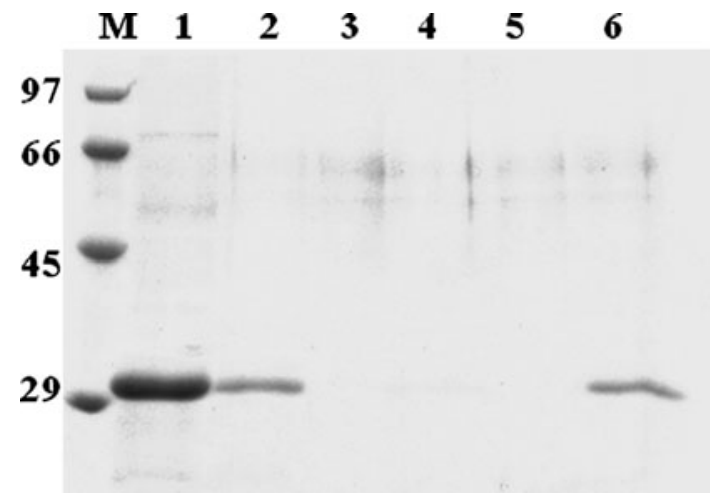

Fig. 5 Interaction of recombinant FopA with peptidoglycan purified from A. ferrooxidans. His-tagged FopA was incubated with peptidoglycan as described in "Materials and methods". After an ultracentrifugation of the reaction mixture, the pellet (lane 2) and the supernatant (lane 5) fractions were analyzed by SDS-PAGE. Recombinant FopA (lane 1), purified peptidoglycan (lane 3), and a pellet obtained by an ultracentrifugation of recombinant FopA solution (lane 4) were analyzed. A reaction mixture without peptidoglycan was similarly incubated and ultracentrifuged. The resulting supernatant was also analyzed (lane 6 ). The gel was stained with Coomassie Blue. Molecular masses in $\mathrm{kDa}$ are indicated on the left. Lane $M$ maker proteins

On the other hand, FopA is thought to be an OmpA family protein based on the amino acid sequence.

The apparent molecular mass of the FopA protein synthesized in A. ferrooxidans and the recombinant FopA protein in $E$. coli both appeared to be approximately $30 \mathrm{kDa}$. This is larger than the molecular mass of approximately $20 \mathrm{kDa}$ predicted from the deduced amino acid sequence. The discrepancy between the apparent molecular mass determined by SDS-PAGE and that predicted for the mature protein has been reported in many outer membrane proteins. Some peptidoglycan-associated lipoproteins show this size discrepancy due to posttranslational lipid modification. RmpM from Neisseria meningitidis is also an OmpA-like protein with a short N-terminal region similar to FopA and does not show a heat-modifiable characteristic (Supplementary Fig. 1). Although RmpM has no modifiable N-terminal cysteine residue which could accept a lipidic moiety (Grizot and Buchanan 2004), it shows the size discrepancy (Klugman et al. 1989), similar to the FopA protein. This size discrepancy of the RmpM protein has been reported to be due to the unusual and unexplained electrophoretic mobility in polyacrylamide in the presence of SDS (Klugman et al. 1989). Recently, a global analysis of gel mobility of proteins of the fission yeast proteome has been reported (Shirai et al. 2008). Hydrophilic and acidic proteins (those for which isoelectric points are less than 6.0) are thought to tend to exhibit mobility smaller than calculated. However, FopA is a hydrophobic (content of hydrophobic amino acid is $54.2 \%$ ) and basic ( $\mathrm{p} I$ is 9.5$)$ protein and is not a 
lipoprotein. Therefore, we can not now clearly explain the reason for the size discrepancy of the FopA protein.

Although most of the OmpA homologs have not been thought to exist as an oligomer, the major outer membrane proteins Pgm6 and Pgm7, which have a high degree of similarity to OmpA (Supplementary Fig. 1), in Porphyromonas gingivalis have been demonstrated to form heterotrimers as a stable structure (Nagano et al. 2005). RmpM is also thought to stabilize the oligomeric state of the porins, PorA or PorB, by associating with the N-terminal region of RmpM in the outer membrane (Grizot and Buchanan 2004). Since FopA is an OmpA-like protein and one of the major outer membrane proteins, it was expected to show a heatmodifiable characteristic and to function as a major anchor protein connecting outer membrane to peptidoglycan. Contrary to our expectation, FopA did not show a heatmodifiable characteristic (Figs. 1, 2). However, as expected, FopA was detected in the peptidoglycan complex (Fig. 4), and the recombinant FopA showed the binding activity to the peptidoglycan prepared from A. ferrooxidans (Fig. 5). Although the two forms of FopA, probably monomeric and oligomeric forms, were detected by Western blot analysis in this study (Fig. 2), the oligomeric form was thought to be the native and stable structure in the outer membrane of A. ferrooxidans. The detection of Omp40 and $\mathrm{Cyc} 2$ in the peptidoglycan-protein complex from A. ferrooxidans implied an association of FopA with these proteins. In contrast to the native FopA from A. ferrooxidans, the recombinant FopA did not form oligomeric structures in the $E$. coli membrane (Fig. 3). Since OmpA of E. coli exists as a monomer in the outer membrane, outer membrane proteins of E. coli may not have an ability to interact or associate with OmpA or OmpA-like proteins.

Recently, an iron-oxidizing/oxygen-reducing supercomplex was isolated from A. ferrooxidans (Castelle et al. 2008). The complex contained almost all components necessary for the iron-oxidizing/oxygen-reducing activity and proteins necessary for the energy-consuming reduction of $\operatorname{NAD}(\mathrm{P})^{+}$, such as two cytochromes $c$ (Cyc2 and Cyc1), a rusticyanin, an $a a_{3}$-type cytochrome $c$ oxidase, and proteins in $b c_{1}$ complex. Besides the proteins, FopA and Omp40 were also detected in the supercomplex. Although Omp40 does not have a peptidoglycan-binding domain, Omp40 was detected in peptidoglycan-protein complex in this study (Fig. 4). Since FopA was thought to exist as an oligomeric form in the outer membrane, detections of FopA and Omp40 in iron-oxidizing/oxygen-reducing supercomplex (Castelle et al. 2008) and the peptidoglycanprotein complex (this study) implied the interaction of FopA with Omp40. Since FopA is one of the major proteins in the A. ferrooxidans outer membrane and is not expected for its channel-forming ability due to the short $\mathrm{N}$-terminal region, FopA probably acts as a stabilizer of the iron-oxidizing/oxygen-reducing supercomplex by interacting with components of the supercomplex and with peptidoglycan.

We have already reported that the synthesis of ironoxidizing enzymes was repressed in sulfur-grown cells and the synthesis of tetrathionate hydrolase was induced in cells grown elemental sulfur (Wakai et al. 2004; Kanao et al. 2007). Western blot analysis revealed no significant difference in the amount of FopA in the outer membranes from iron-grown cells and sulfur-grown cells. Although a peptidoglycan-protein complex was prepared from irongrown cells and used in this study, tetrathionate hydrolase may be detected in a peptidoglycan-protein complex prepared from sulfur-grown cells. Further studies are needed to make clear the contribution of FopA to stabilization of iron- or sulfur-oxidizing enzyme systems.

Acknowledgments We thank S. Tamaru in Central Research Laboratory, Okayama University Medical School for determining the $\mathrm{N}$-terminal amino acid sequences.

Open Access This article is distributed under the terms of the Creative Commons Attribution Noncommercial License which permits any noncommercial use, distribution, and reproduction in any medium, provided the original author(s) and source are credited.

\section{References}

Achouak W, Heulin T, Pages JM (2001) Multiple facets of bacterial porins. FEMS Microbiol Lett 99:1-7

Bouveret E, Bénédetti H, Rigal A, Loret E, Lazdunski C (1999) In vitro characterization of peptidoglycan-associated lipoprotein (PAL)-peptidoglycan and PAL-TolB interactions. J Bacteriol 181:6306-6311

Castelle C, Guiral M, Malarte G, Ledgham F, Leroy G, Brugna M, Giudici-Orticoni MT (2008) A new iron-oxidizing $/ \mathrm{O}_{2}$-reducing supercomplex spanning both inner and outer membranes, isolated from the extreme acidophile Acidithiobacillus ferrooxidans. J Biol Chem 283:25803-25811

Fjellbirkeland A, Kleivdal H, Joergensen C, Thestrup H, Jensen HB (1997) Outer membrane proteins of Methylococcus capsulatus (Bath). Arch Microbiol 168:128-135

Grizot S, Buchanan SK (2004) Structure of OmpA-like domain of RmpM from Neisseria meningitides. Mol Microbiol 51:1027-1037

Guiliani N, Jerez CA (2000) Molecular cloning, sequencing, and expression of omp-40, the gene coding for the major outer membrane protein from the acidophilic bacterium Thiobacillus ferrooxidans. Appl Environ Microbiol 66:2318-2324

Heller KB (1978) Apparent molecular mass of a heat modifiable protein from the outer membrane of Escherichia coli in gels with different acrylamide concentration. J Bacteriol 134:1181-1182

Jap BK, Walian PJ (1996) Structure and functional mechanism of porins. Physiol Rev 76:1073-1088

Kamimura K, Yamakado M, Shishikado T, Sugio T (2004) Analysis of salt-induced outer membrane proteins in Acidithiobacillus ferrooxidans NASF-1. In: Tsezos $\mathrm{M}$, Hatzikioseyian $\mathrm{A}$, Remoundaki E (eds) Biohydrometallurgy, a sustainable technology in evolution part II. Symposium proceedings. Proceedings of 
the 15th international biohydrometallurgy symposium IBS 2003. Athens, Greece, pp 1261-1269

Kanao T, Kamimura K, Sugio T (2007) Identification of a gene encoding a tetrathionate hydrolase in Acidithiobacillus ferrooxidans. J Biotechnol 132:16-22

Klugman KP, Gotschlich EC, Blake MS (1989) Sequence of the structural gene $(\mathrm{rmpM})$ for the class 4 outer membrane protein of Neisseria meningitidis, homology of the protein to Gonococcal protein III and Escherichia coli PmpA, and construction of Meningococcal strains that lack class 4 protein. Infect Immun 57:2066-2071

Koebnik R, Locher KR, Van Gelder P (2000) Structure and function of bacterial outer membrane proteins: barrels in a nutshell. Mol Microbiol 37:239-253

Morona R, Klose M, Nenning U (1984) Escherichia coli K-12 outer membrane protein $(\mathrm{OmpA})$ as a bacteriophage receptor: analysis of mutant genes expressing altered proteins. J Bacteriol 159:570-578

Nagano K, Read EK, Murakami Y, Masuda T, Noguchi T, Yosimura F (2005) Trimeric structure of major outer membrane proteins homologous to OmpA in Porphyromonas gingivalis. J Bacteriol 167:902-911

Nikaido H (2003) Molecular basis of bacterial outer membrane permeability revisited. Microbiol Mol Biol Rev 67:593-656

Rawlings DE (2002) Heavy metal mining using microbes. Annu Rev Microbiol 56:65-91

Rodriguez M, Campos S, Gomez-Silva B (1986) Studies on native strains of Thiobacillus ferrooxidans. III. Studies on the outer membrane of Thiobacillus ferrooxidans. Characterization of the lipopolysaccharide and some proteins. Biotechnol Appl Biochem 8:292-299

Rohwerder T, Gehrke T, Kinzler K, Sand W (2003) Bioleaching review part A: progress in bioleaching: fundamentals and mechanism of bacterial metal sulfide oxidation. Appl Microbiol Biotechnol 63:239-248

Schulz GE (2002) The structure of bacterial outer membrane proteins. Biochim Biophys Acta 1565:308-317
Shirai A, Matsuyama A, Yashiroda Y, Hashimoto A, Kawamura Y, Arai R, Komatsu Y, Horinouchi S, Yoshida M (2008) Global analysis of gel mobility of proteins and its use in target identification. J Biol Chem 283:10745-10752

Silva M, Ferreira A, Rodriguez M, Wolff D (1992) The major Thiobacillus ferrooxidans outer membrane protein forms low conductance ion channels in planar lipid bilayers. FEBS Lett 296:169-173

Smith SGJ, Mahon V, Lambert MA, Fagan RP (2007) A molecular swiss army knife: OmpA structure, function and expression. FEMS Microbial Lett 273:1-11

Sonntag I, Schwartz H, Hirota Y, Henning U (1978) Cell envelope and cell shape of Escherichia coli: multiple mutants missing the outer membrane lipoprotein and other major outer membrane proteins. J Bacteriol 136:280-285

Sugawara E, Nikaido H (1994) OmpA protein of Escherichia coli outer membrane occurs in open and closed channel forms. J Biol Chem 269:17981-17987

Wakai S, Kikumoto M, Kanao T, Kamimura K (2004) Involvement of sulfide:quinone oxidoreductase in sulfur oxidation of an acidophilic iron-oxidizing bacterium, Acidithiobacillus ferrooxidans NASF-1. Biosci Biotechnol Biochem 68:2519-2528

Wakai S, Tsujita M, Kikumoto M, Manchur MA, Kanao T, Kamimura K (2007) Purification and characterization of sulfide:quinone oxidoreductase from an acidophilic iron-oxidizing bacterium, Acidithiobacillus ferrooxidans. Biosci Biotechnol Biochem 71:2735-2742

Yarzábal A, Brasseur G, Ratouchniak J, Lund K, Lemesle-Meunier D, DeMoss JA, Bonnefoy V (2002) The high-molecular-weight cytochrome $c$ Cyc2 of Acidithiobacillus ferrooxidans is an outer membrane protein. J Bacteriol 814:313-317

Yarzábal A, Appia-Ayme C, Ratouchniak J, Bonnefoy V (2004) Regulation of the expression of the Acidithiobacillus ferrooxidans rus operon encoding two cytochrome $c$, a cytochrome oxidase and rusticyanin. Microbiology 150:2113-2123 